\title{
MODELLING AND SIMULATION OF STRAIN RESISTANCE OF ALLOYS TAKING INTO ACCOUNT BARRIER EFFECTS
}

\author{
A. S. Smirnov ${ }^{1}$, A. V. Konovalov ${ }^{1}$, O. Yu. Muizemnek ${ }^{1}$ \\ ${ }^{1}$ Institute of Engineering Science, Ural Branch of the Russian Academy of Sciences, 34 Komsomolskaya st., \\ Ekaterinburg, Russian Federation
}

"Corresponding author. E-mail: smirnov@imach.uran.ru; address for correspondence: ul. Komsomolskaya 34, 620049, Ekaterinburg, Russian Federation. Tel.: +7 (343) 375-35-89; fax: +7 (343) 374-53-30

The paper proposes a model of strain resistance of alloy under high-temperature deformation. The model describes hardening of alloy due to the increase of dislocation density, as well as the barrier effect of blocking free dislocations, boundaries of grains and subgrains by dispersoids. The model also takes into account the softening processes associated with the recovery and dynamic recrystallization. The model has been tested on the rheological behavior of an Al-Mg alloy named $\mathrm{AMg} 6$ at temperatures of 400 and $500{ }^{\circ} \mathrm{C}$ in the range of strain rates from 5 to $25 \mathrm{~s}^{-1}$. It was found in this temperature - strain rate range that the curve of strain resistance of the AMg6 alloy consists of several portions. First there is hardening of the material, then there is material softening, which is again replaced by hardening of the material. With the use of the electron backscatter diffraction technique and transmission electron microscopy, it was found that the main process of softening at investigated temperatures is dynamic recrystallization. The appearance of the second portion of hardening on the strain resistance curve is the inhibition of dynamic recrystallization, as well as manifestation of the barrier effect of blocking free dislocations, grain and subgrain boundaries by dispersoids.

Keywords: Al-Mg alloy, AMg6, strain resistance model, strain resistance, rheology, high temperature deformation, recrystallization, microstructure, dispersoids, barrier effect.

\section{Introduction}

Processes associated with material hardening and softening occur in metal materials under deformation at high temperatures. Depending on temperature - strain rate conditions of deformation, dynamic recovery, polygonization or recrystallization may prevail in a material, or these processes can take place simultaneously in different or equal portions [1-3]. The main mechanism of hardening in alloys is the process associated with an increase in the dislocation density and impeding the motion of free dislocations. The softening process can be inhibited due to the barrier effect connected with blocking free dislocation motion by impurity atoms and inclusions and with the growth of grains and subgrains by pinning on various inclusions [4]. The barrier effect of free dislocation blocking is usually associated with the Portevin-Le Chatelier and Savart-Masson effects and the inverse relation between strain resistance and strain rate [5-13]. The inhibition or blocking of grain and subgrain boundaries on inclusions generally occurs in metal matrix composites and high alloys [7, 11, 12, 14-24].

The physical processes of hardening and softening occurring under deformation change the form of the strain resistance curve and affect the final physical-mechanical properties of alloys $[2,25]$. For example, the impeded growth of grains under deformation results in the prevalence of a certain grain orientation over the others thus improving the mechanical properties of products in this direction, and this may have a positive effect in the designing of crucial products. The barrier effect of dislocations blocked by inclusions or impurity atoms, as a rule, has a negative influence on the final technological properties, such as lower corrosion-resistance, strength and fatigue strength $[13,26-28]$. Since the processes of structure formation affect the strain resistance curve, a mathematical model of strain resistance should include components describing the physical processes of hardening and softening. A large number of models have already been proposed in the literature, 
which take into consideration separately the influence of discontinuous dynamic recrystallization [29-37], in-situ recrystallization [38-41] or the Portevin-Le Chatelier effect [5-7] on strain resistance. However, in the literature we have not found any models of strain resistance for alloys under high-temperature deformation that would describe the combined influence of hardening, recovery, recrystallization and barrier effects.

Previously, we developed and tested a model of strain resistance for a number of aluminum alloys and steels with an fcc lattice [42-44] within a wide temperature - strain rate range. The ability of the model to predict the part of the dynamic recrystallization with acceptable engineering precision under time-varying strain rate of the specimen was shown in [45].

The paper proposes a new rheological model of strain resistance, which is based on the model found in [45] and takes into account the viscous properties of an alloy under plastic deformation, its softening due to recovery and recrystallization and its hardening due to the barrier effect of blocking the motion of free dislocations and the growth of recrystallized grains by inclusions. The model has been identified by experimental data obtained for the AMg6 alloy.

\section{Material and investigation procedure}

Cylindrical specimens with a diameter of $8 \pm 0.1 \mathrm{~mm}$ and a height of $12 \pm 0.1 \mathrm{~mm}$ were machined from 10-mm AMg6 alloy rod (Al 92.4; Mg 6.56; Fe 0.27; $\mathrm{Si}$ 0.16; $\mathrm{Cu} 0.013$; Mn 0.05; Ti 0.04 ; Zn 0.02; Be $0.0012 \%$ ). They were compressed at 400 and $500{ }^{\circ} \mathrm{C}$ by a cam plastometer installed in the "Plastometriya" center for collective use at the Institute of Engineering Science, UB RAS. The specimens were annealed in vacuum at $500{ }^{\circ} \mathrm{C}$ for 4 hours before deformation.

To avoid heat losses during testing, the specimen was wrapped by kaolin wool and placed into a metal container together with heads. The container with the specimen inside was heated in an electric furnace up to the temperature of testing and then transferred from the furnace to the working space of the apparatus where the specimen was deformed. The specimen temperature during heating and the temperature variations inside the container during testing were monitored by a chromel-alumel thermocouple. Since we could not avoid specimen temperature fall while transferring the container from the furnace to the start of compression, the specimens were overheated to 4 degrees above the intended testing temperature. As a result, the guaranteed temperature for the beginning of deformation was $400 \pm 2$ and $500 \pm 2{ }^{\circ} \mathrm{C}$. Graphite was used as a lubricant between the specimen and the heads, with the Coulomb friction coefficient $\mu=0.1$ at temperatures ranging between 300 and $400{ }^{\circ} \mathrm{C}$ and $\mu=0.15$ at $500^{\circ} \mathrm{C}$ for aluminum alloys.
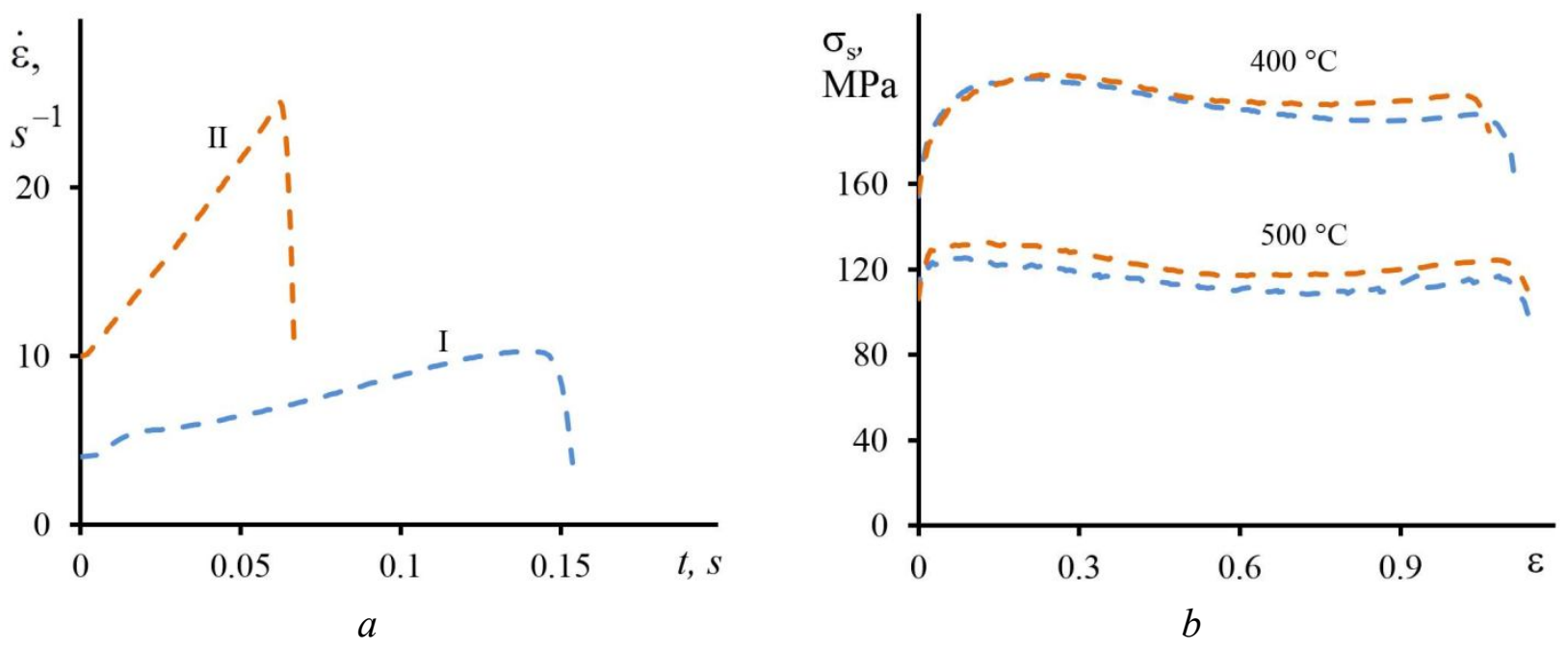

Fig. 1. Experimental curves representing strain rate $\dot{\varepsilon}$ as dependent on deformation time $t(a)$ and strain resistance $\sigma_{s}$ as dependent on the amount of strain $\varepsilon(b)$. The blue curve corresponds to loading form I, and the orange curve corresponds to loading form II. 
The dotted curves in Fig. 1 show experimental data on compression. While constructing the graphical dependences, we consider that the experiment deals with a uniaxial stress state. The specimen strain rate $\dot{\varepsilon}$ is calculated as

$$
\dot{\varepsilon}(t)=\dot{h}(t) / h(t)
$$

where $h(t)$ is the current height of the specimen at a time moment $t, h(t)=h_{0}-\Delta h(t)$. Strain resistance $\sigma_{s}$ is calculated by the formula

$$
\sigma_{s}(t)=P(t) / F(t)
$$

where $P(t)$ is the current pressing force; $F(t)$ is the current specimen cross-sectional area determined from the constant volume condition for the specimen and the assumption of its strain homogeneity under uniaxial stress, $F(t)=\frac{\pi d_{0}^{2} h_{0}}{4 h(t)}\left(h_{0}\right.$ is the initial height of the specimen; $d_{0}$ is the initial diameter of the specimen). It is obvious from Fig. $1 a$ that the strain rate of the specimens was varied during the experiment. The necessity of compressing specimens with variable strain rate within one experiment is a peculiarity of the model parameter identification procedure based on the principles of dynamic object identification. According to these principles, only one experiment is in principle enough to evaluate the parameters of a mathematical model, see [46]. The obtained parameter values are valid only in the investigated interval of strain rates. To extend this interval, experiments for each temperature were carried out with realizing two different functions of timevarying strain rate (hereinafter referred to as loading form) presented in Fig. 1 $a$, at least four experiments being made for each form.

The microstructure was studied by the method of electron backscattered diffraction (EBSD) with the use of a MIRA 3 TESCAN raster electron microscope with an OXFORD HKLNordlysF+ detachable device installed at the Institute of Engineering Science, Russian Academy of Sciences (Ural Branch), and by the method of transmission electron microscopy (TEM) with the use of a JEM200CX microscope installed at the Testing Center for Nanotechnologies and Advanced Materials, a collective use center belonging to the Institute of the Physics of Metals, Russian Academy of Sciences (Ural Branch). The scanning step for the EBSD analysis was $300 \mathrm{~nm}$. The microstructure analysis was made by one representative specimen in a series of similar experiments. We assumed that the grains had misorientation exceeding $15^{\circ}$ and that the subgrain misorientation ranged from 2 to $15^{\circ}$. When restoring the specimen microstructure, we assumed that a grain could not be smaller than the double step of scanning, i.e. each grain must have at least two points with a certain crystallographic direction. The volume portion of dynamic recrystallization that had occurred was calculated with the use of data on the mean misorientation of the lattice inside a grain $\Theta_{\text {mid }}$ and the critical misorientation angle $\Theta_{\max }$ [47]. In [45] a technique for calculating $\Theta_{\max }$ was proposed, and its value for the AMg6 alloy was found to be $1.3^{\circ}$. To determine the value of $\Theta_{\max }$, the middle misorientation angle $\Theta_{\text {mid }}$ was calculated for each grain. Then, using a search with a step of 0.05 , we calculated the critical misorientation angle $\Theta_{\max }$ so that the increase or decrease in the value of $\Theta_{\max }$ does not turn the deformed grains into recrystallized grains, and vice-versa. Figure 2 shows an example of determining recrystallized and deformed grains. The portion of dynamically recrystallized grains $V_{\text {exp }}$ is here calculated as the ratio between the total area of recrystallized grains and the total area of grains. 

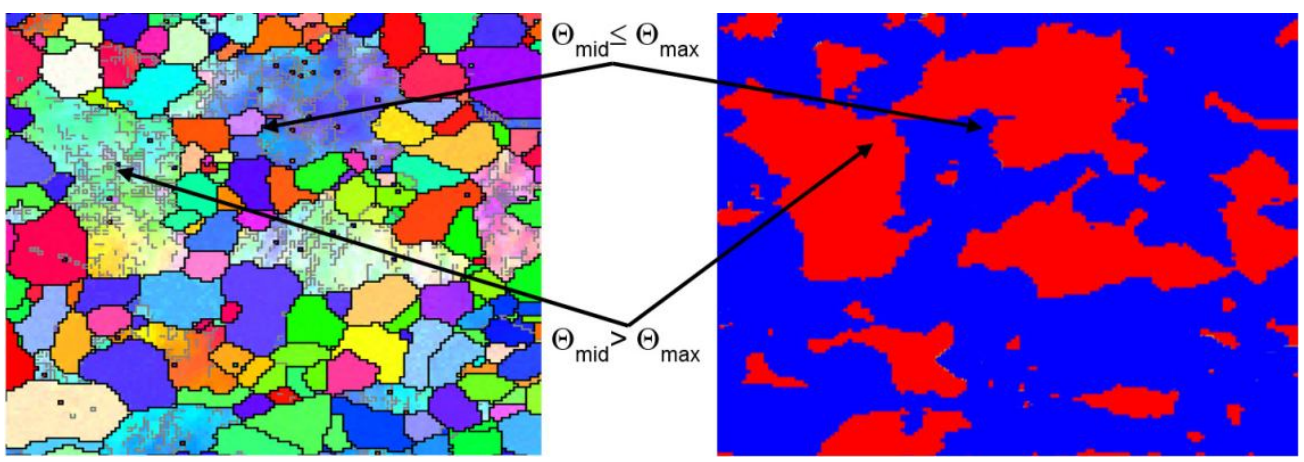

Fig. 2. An example of determining the recrystallized (blue) and deformed (red) grains when $\Theta_{\max }=1.3^{\circ}$

\section{Results and discussion}

\subsection{Analysis of hardening and softening}

The specimen microstructure was analyzed in the specimen center. Figure 3 shows the microstructure before and after deformation of the specimens. On the microstructure images in Fig. 3, the pixel color corresponds to definite crystallographic orientation. Each crystallographic orientation is represented in the color scale of the inverse pole figure, see Fig. $3 d$.

Figure $3 a$ shows the microstructure of the AMg6 alloy specimen before deformation. It is obvious from the microstructure images that in the specimen center there are large elongated grains. Figs $3 b$ and $3 c$ demonstrate the microstructure images in the center of the specimens compressed according to form II (Fig. 1) at temperatures of 400 and $500{ }^{\circ} \mathrm{C}$, respectively. Figure 4 shows a distribution map of deformed and recrystallized grains at $\Theta_{\max }=1.3^{\circ}$ after specimen compression. In Figs 3 and 4 big black spots symbolize areas with indefinite crystallographic orientation and, generally, they are dispersoids. According to [48], the dispersoids may be the following compounds: $\mathrm{Al}_{3} \mathrm{Mg}_{2}, \mathrm{Al}_{6} \mathrm{Mn}, \mathrm{Mg}_{2} \mathrm{Si}$ and $\mathrm{AlFeSiMn}$.

Figure 4 shows that the portion represented by recrystallized grains in the residual microstructure of the deformed specimens is significant. Thus the volume portion of dynamic recrystallization $V_{\text {exp }}$ is $82 \%$ for $400{ }^{\circ} \mathrm{C}$ and $90 \%$ for $500{ }^{\circ} \mathrm{C}$. The portion of dynamically recrystallized grains is here calculated as the ratio between the total area of recrystallized grains and the total area of grains. 
opter-aceEss jürnal

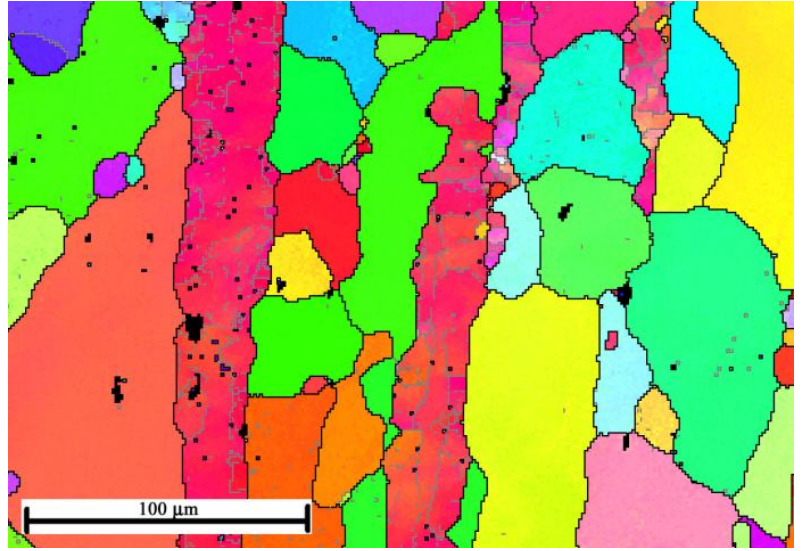

$a$

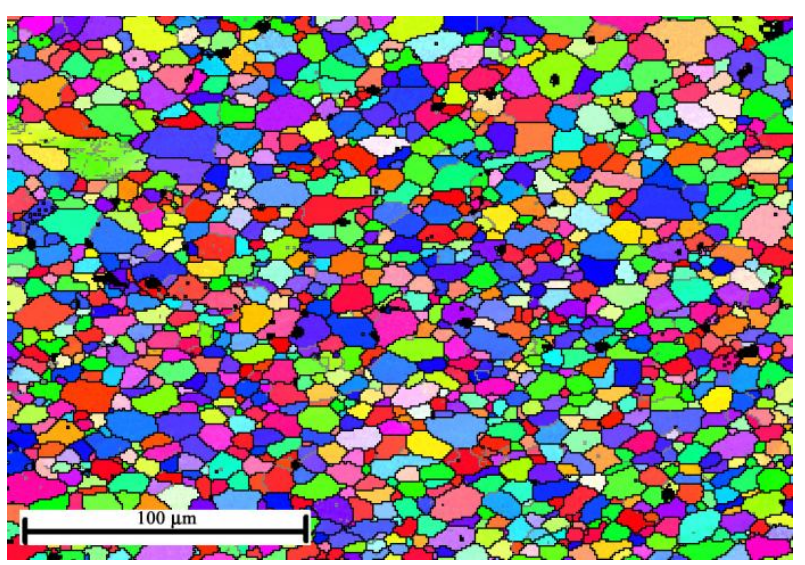

$c$

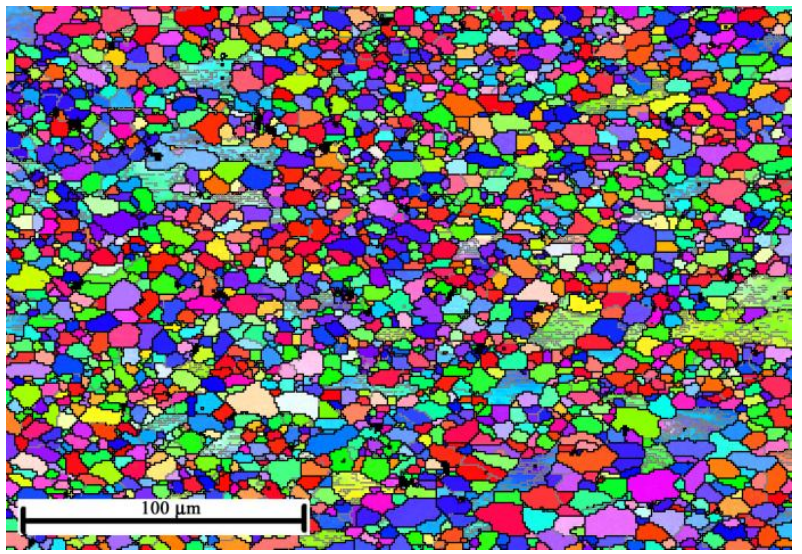

$b$

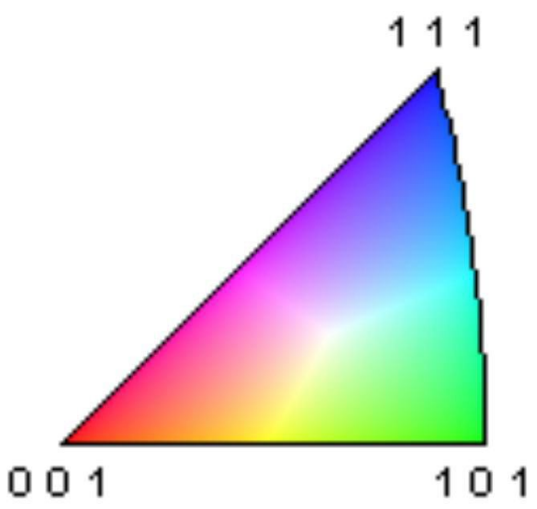

$d$

Fig. 3. The microstructure of an AMg6 alloy specimen in the central zone before deformation $(a)$ and after deformation according to loading form II (Fig. $1 a$ ) at $400(b)$ and $500{ }^{\circ} \mathrm{C}(c)$. The inverse pole figure $(d)$

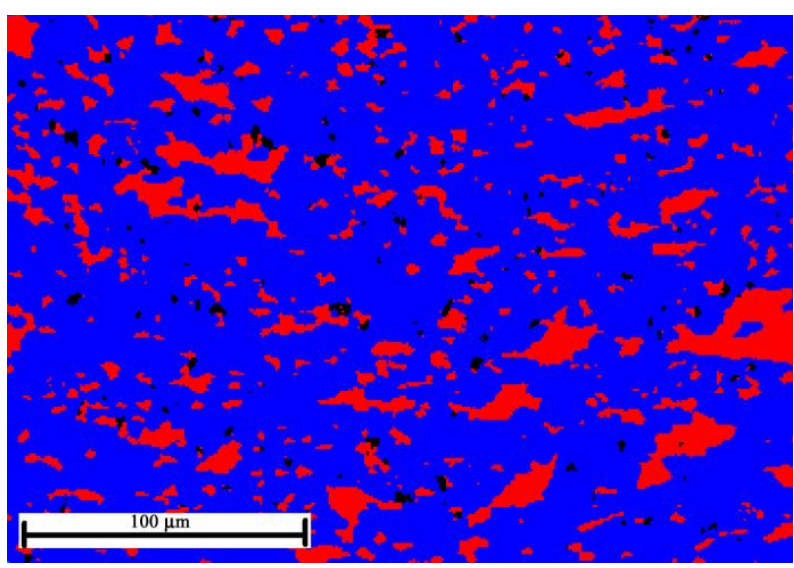

$a$

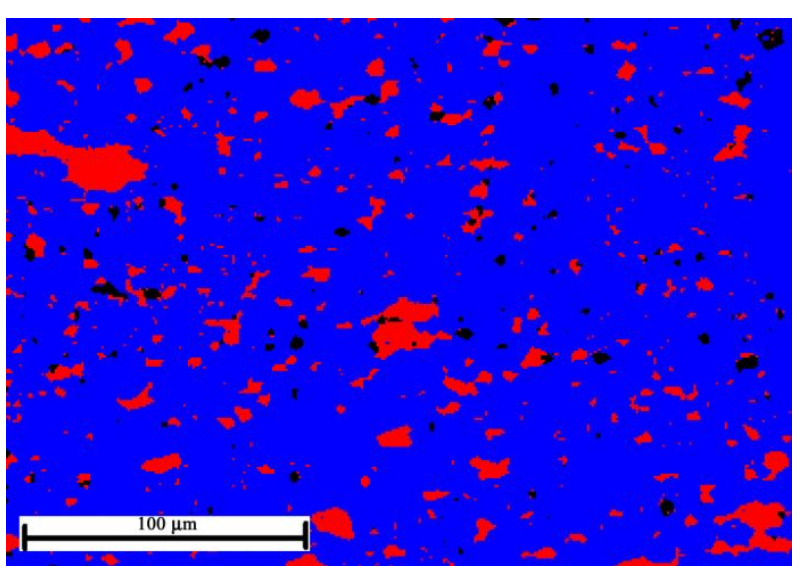

$b$

Fig. 4. A distribution map for deformed and recrystallized grains after deformation at $400(a)$ and $500{ }^{\circ} \mathrm{C}(b)$. The red color shows deformed grains; the blue color shows recrystallized grains 


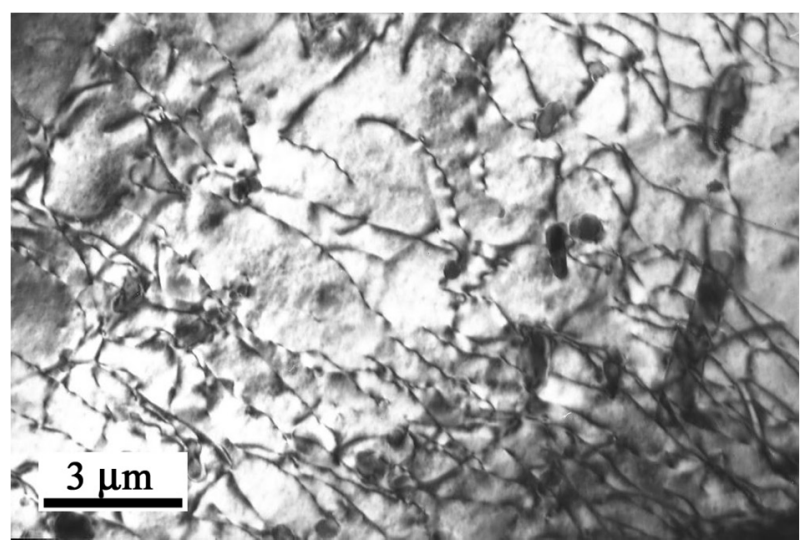

Fig. 5. Dispersoids and dislocations in the AMg6 alloy

The presence of a large fraction of recrystallized grains in the residual microstructure suggests that, at high strain, the growth of the grains was delayed by the growth of the neighboring grains [1-3]. As a result, the rate of material softening gradually decreased and that may cause material hardening. However, material hardening may be induced not only by decelerating recrystallization, but also by the presence of a large number of inclusions in the specimen microstructure. These inclusions block the motion of free dislocations and prevent the motion of boundaries and subboundaries. In the specimen microstructure before and after deformation, there are dispersoids sized between $60 \mathrm{~nm}$ and $2 \mu \mathrm{m}$, see Fig. 5. According to the images made by a transmission electron microscope, there doesn't seem to be a noticeable change in the number of dispersoids in the microstructure during deformation. Therefore all the dispersoids in the alloy were formed in the previous stages of material treatment. However, the large density of dispersoids gives rise to a significant number of areas where dislocations, which were involved in plastic deformation, were blocked and that is certain to have resulted in the hardening of the material.

\subsection{Strain resistance model}

The paper [42] proposed a strain resistance model describing the rheological behavior of alloys in conditions when an alloy exhibited viscous properties during plastic deformation, when hardening took place due to increasing dislocation density and softening occured due to dynamic recrystallization and recovery. The works [44, 45 and 49] showed that the developed model described, with a good accuracy, the rheology of the AMg6 alloy at a temperature of $300{ }^{\circ} \mathrm{C}$ in a wide strain rate range. It was found that the main process of softening was dynamic recrystallization, which occurred to a significantly smaller degree than at temperatures of 400 and $500{ }^{\circ} \mathrm{C}$. At strain temperatures of 400 and $500{ }^{\circ} \mathrm{C}$, the recrystallization was active, and the influence of the barrier effect on the growth of grains and the blocking of free dislocations increased. As a result, the absence of structural constituents in the strain resistance model, which would describe the barrier effect, caused the incorrect description of the strain resistance curve.

A new strain resistance model has been made on the basis of the previously developed model described in [45]. The entire volume of an alloy is divided into three portions named $V_{r}, V_{p}$ and $V_{n}$. The value $V_{r}$ is the volume portion with dynamic recrystallization; the value $V_{p}$ is the volume portion with dislocations blocked by dispersoids and impurity atoms; the value $V_{n}$ is equal to the remaining portion of the alloy volume. This decomposition satisfies the equality

$$
V_{n}+V_{r}+V_{p}=1
$$

At the initial moment of time before deformation, 


$$
V_{n}=1, \quad V_{r}=0, \quad V_{p}=0 .
$$

It is assumed that all the plastic deformation is concentrated in the volume $V_{n}$, that the increment of yield stress due to the shear $k$ in the Mises plasticity condition is attributed to plastic deformation and that this increment is proportional to the volume $V_{n}$, the increment of dislocation density and the volume $V_{p}$.

During plastic deformation, free dislocations involved in plastic deformation are pinned by dispersoids or impurity atoms thus causing material hardening [4, 13]. At the same time, at high temperatures due to high mobility of dislocations, dynamic recovery occurs actively, and this results in the annihilation of pinned dislocations and, as a consequence, in the reduction of the volume $V_{p}$. Thus, during plastic deformation, the volume $V_{p}$ can both increase and decrease due to two competing processes.

Based on the above, the strain resistance model taking into account the barrier effects is presented in the following form:

$$
\begin{aligned}
& \sigma_{s}=\sqrt{3} k+\frac{\sqrt{3}}{2} q ; \\
& k=a_{0}+\rho V_{n}\left(a_{10}+a_{11} V_{p}\right)^{a_{12}} ; \\
& \dot{\rho}=a_{1} \exp \left(-a_{2} \rho\right) \dot{\varepsilon}-a_{3} \rho ; \\
& \dot{V}_{p}=a_{13} \dot{\varepsilon}-a_{14} \frac{V_{n}}{1+\rho} ; \\
& \dot{V}_{r}=\left\{\begin{array}{l}
\dot{V}_{r}^{*}\left(\frac{1-V_{r}}{1-a_{6}}\right)^{a_{7}} \frac{d R}{d t} \quad \text { if } V_{r} \leq a_{6} ; \\
\dot{V}_{r}^{*} \quad \text { if } V_{r}>a_{6} ; \\
\varepsilon_{r}=\int_{r}=a_{6} ; \\
q=a_{8} \ln d t ; \quad \frac{d R}{d t}=\dot{\varepsilon} \rho \quad \text { when } \quad \rho>a_{4} ;
\end{array}\right.
\end{aligned}
$$

Here $q$ is a function describing the viscous properties of the material; $\rho$ is the quantity proportional to the dislocation density increment induced by plastic deformation; $\dot{\varepsilon}$ is strain rate (for the uniaxial stress state under compression $\dot{\varepsilon}=|v| / h ; v$ is the speed of the testing machine grip; $h$ is the current height of the specimen under deformation); $\varepsilon_{r}$ is the strain accumulated before the onset of dynamic recrystallization; $R$ is the radius of a recrystallized grain, $R\left(t_{r}\right)=0, t_{r}$ is the time moment of the dynamic recrystallization onset defined by the condition $\rho=a_{4} ; a_{i}(i=0, \ldots, 14)$ are the model parameters to be identified by the experimental data. The dot above the symbols indicates a time derivative.

The system of equations (5), together with conditions (3) and (4), represents the physicalmechanical hierarchical rheological model describing, in the aggregate, the viscous and plastic properties of a medium. The model deals with plastic hardening due to the dislocation density increment and the blocking of the motion of free dislocations by dispersoids, as well as softening due to dynamic recovery and recrystallization. 


\subsection{Identification of the strain resistance model}

The model parameters have been found by minimizing the root-mean-square deviation of the calculated values of strain resistance $\sigma_{s}(t)$ from the experimental ones $z(t)$ simultaneously with respect to two experimental strain resistance curves for each temperature separately, as

$$
J\left(a_{0}, \ldots, a_{14}\right)=\sum_{j=1}^{2} \int_{0}^{T}\left[\sigma_{s}(t)-z(t)\right]^{2} d t,
$$

where $T$ is the time of specimen deformation. The identification results for the strain resistance model are shown in Fig. $6 b$ by solid lines. The model parameters are given in the Table.

Table - The parameters of the strain resistance model

\begin{tabular}{|c|c|c|c|c|c|c|c|c|c|c|c|c|c|c|c|}
\hline$T,{ }^{\circ} \mathrm{C}$ & $a_{0}$ & $a_{1}$ & $a_{2}$ & $a_{3}$ & $a_{4}$ & $a_{5}$ & $a_{6}$ & $a_{7}$ & $a_{8}$ & $a_{9}$ & $a_{10}$ & $a_{11}$ & $a_{12}$ & $a_{13}$ & $a_{14}$ \\
\hline 400 & 64 & 10125 & 0.03 & 0.003 & 8.2 & 0.009 & 0.254 & 4.58 & 13.8 & 3.6 & 0.3 & 1.4 & 1.13 & 0.04 & 0.14 \\
\hline 500 & 44 & 10577 & 0.02 & 86.747 & 14.7 & 0.021 & 0.67 & 2.52 & 13.4 & 1.9 & 0.24 & 0.2 & 1.62 & 0.04 & 0.27 \\
\hline
\end{tabular}

The average relative deviation $\delta$ of the experimental curves from the calculated ones is 1.4 $\%$ for the test temperature of $400{ }^{\circ} \mathrm{C}$ and $1.6 \%$ for the test temperature of $500{ }^{\circ} \mathrm{C}$. The value of $\delta$ is calculated by the formula:

$$
\delta=\frac{1}{N} \sum_{j=1}^{N=2} \frac{\int_{0}^{T_{j}}\left|\sigma_{s}(t)-z(t)\right| d t}{\int_{0}^{T_{j}} z(t) d t} \cdot 100 \%
$$

where $j$ is the experiment number; $N$ is the total number of tests in all the experiments used for identification $(N=2) ; T_{j}$ is the time of specimen deformation for the $j$-th experiment; $z$ denotes the experimental values of strain resistance and $\sigma_{s}$ denotes the values obtained from the identification of the strain resistance model for the $j$-th experiment.
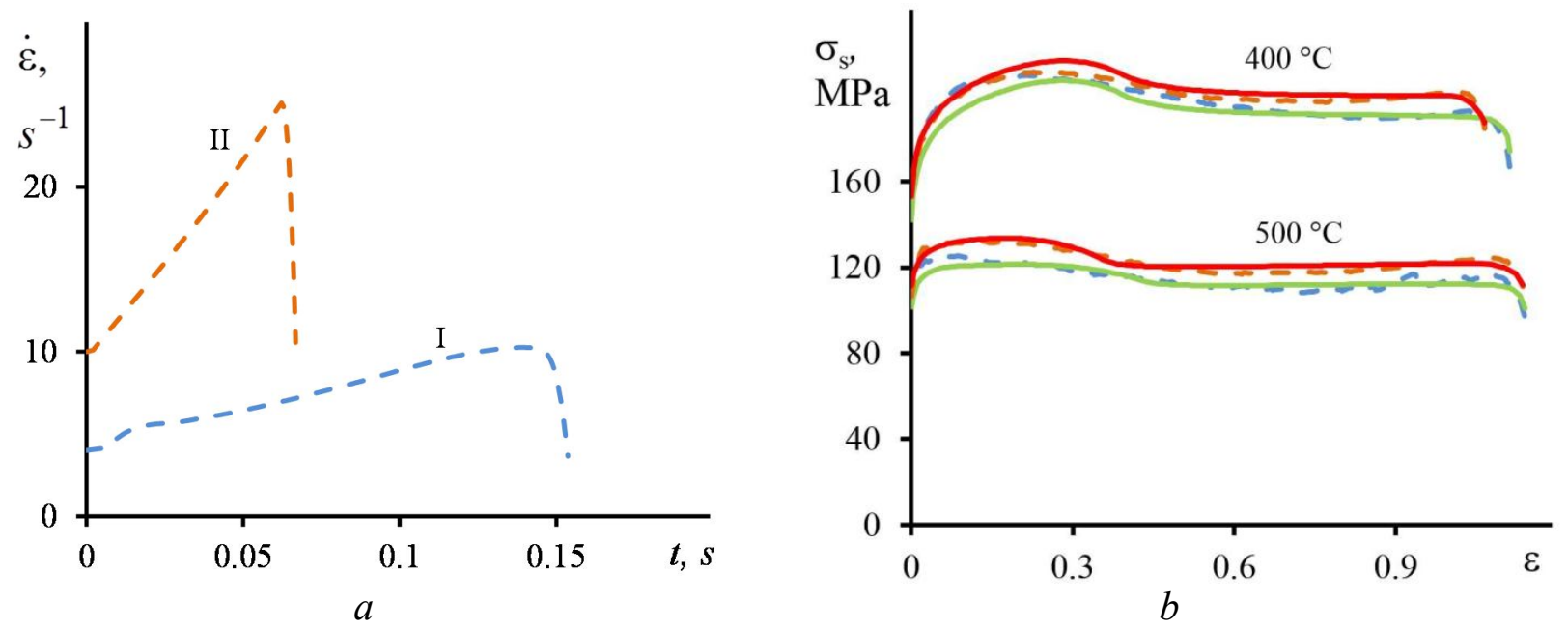

Fig. 6. Strain rate $\dot{\varepsilon}$ as dependent on deformation time $t(a)$; strain resistance $\sigma_{s}$ as dependent on strain $\varepsilon(b)$ 
The experimental data is indicated by the dotted curve and the calculated one is shown by the solid curve. The blue dotted curve corresponds to loading form I and the orange one corresponds to loading form II.

Figure $6 b$ shows that strain resistance increases at the beginning, then reaches its peak value, decreases and increases again. The proposed mathematical model of strain resistance takes into account this rheological behavior of the material. This means that the model reflects qualitatively correctly the physical processes of structure formation in the alloy during deformation.

The obtained parameters of the strain resistance model (see Table) can be used to construct strain resistance curves for a constant strain rate within the range of strain rates used in the experiment. Figure 7 shows strain dependences of strain resistance $\sigma_{s}$ at constant strain rates equal to 5, 10 and $20 \mathrm{~s}^{-1}$.

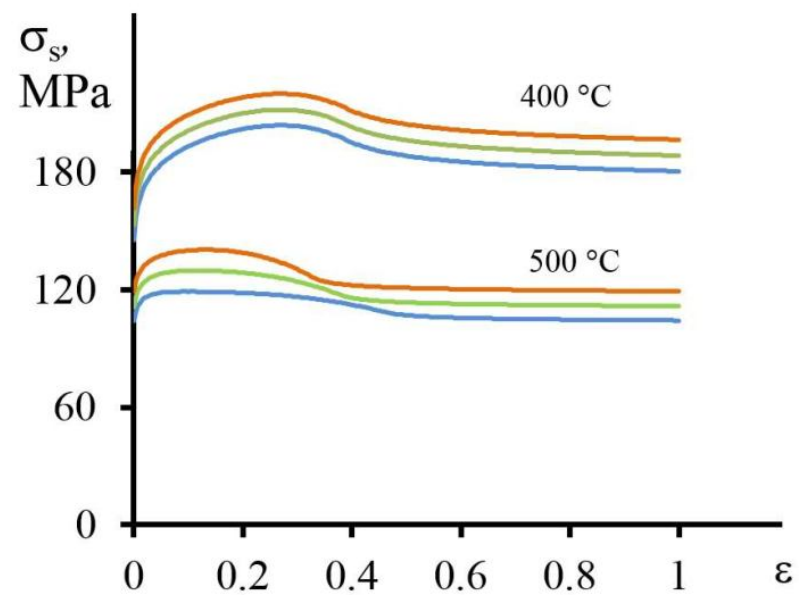

Fig. 7. Strain resistance $\sigma_{s}$ as dependent on strain $\varepsilon$ at a constant strain rate, $\mathrm{s}^{-1}: 5$ (blue curve), 10 (green curve) and 20 (orange curve)

\section{Conclusion}

1. In this paper we have constructed a strain resistance model describing the rheological behavior of alloys at high-temperature plastic deformation when the processes of hardening due to the dislocation density increment, dynamic recovery, recrystallization and the blocking of the motion of free dislocations by inclusions occur simultaneously in a material.

2. It is illustrated by the AMg6 alloy that the strain resistance model qualitatively and quantitatively correctly describes the behavior for the strain resistance curve of the alloy at temperatures of 400 and $500{ }^{\circ} \mathrm{C}$ when $\dot{\varepsilon}=5-25 \mathrm{~s}^{-1}$.

3. Applying the method of electron backscattered diffraction, we have established that the main process of AMg6 alloy softening at temperatures of 400 and $500^{\circ} \mathrm{C}$ when $\dot{\varepsilon}=5-25 \mathrm{~s}^{-1}$ is dynamic recrystallization resulting in the formation of new grains. The volume fraction of dynamic recrystallization is 80 and $90 \%$ of the total volume at test temperatures of 400 and $500{ }^{\circ} \mathrm{C}$, respectively.

4. The appearance of the second hardening segment on the strain resistance curve (see Fig. $1 b$ ) is caused by the slowdown of dynamic recrystallization and the barrier effect of dispersoids blocking free dislocations as well as grain and subgrain boundaries.

\section{Acknowledgments}

The work was partially financially supported by the grant of the RFBR (project 14-08-31262) and the Program of UB RAS (project 13-1-019-RC). 


\section{References}

1. Poluhin P.I., Gorelik S.S., Vorontsov V.K. Fizicheskie osnovy plasticheskoi deformatsii [Basic physics of plastic deformation]. Moscow, Metallurgiya Publ., 1982, 584 p. (In Russian).

2. Gorelik S.S., Dobatkin S.V., Kaputkina L.M. Rekristallizatsiya metallov i splavov [Recrystallization of metals and alloys]. Moscow, MISSIS Publ., 2005, 432 p. (In Russian).

3. Doherty R.D., Hughes D.A., Humphreys F.J., Jonas J.J., Juul Jensen D., Kassner M.E., King W.E., McNelley V.R., McQueen H.J., Rollett A.D. Current issues in recrystallization: A review. Materials Science and Engineering A, 1997, vol. 238, no. 2, pp. 219-274.

4. Babich V.K., Gul Yu.P., Dolzhenkov I.E. Deformatsionnoe starenie stali [Strain aging of steel]. Moscow, Metallurgiya Publ., 1972, 320 p.(In Russian).

5. Hähner P., Rizzi E. On the kinematics of Portevin-Le Chatelier bands: Theoretical and numerical modelling. Acta Materialia, 2003, vol. 51, no. 12, pp. 3385-3397.

6. Rizzi E., Hähner P. On the Portevin-Le Chatelier effect: Theoretical modeling and numerical results. International Journal of Plasticity, 2004, vol. 20, no. 1, pp. 121-165.

7. Anjabin N., Karimi Taheri A., Kim H.S. Simulation and experimental analyses of dynamic strain aging of a supersaturated age hardenable aluminum alloy. Materials Science and Engineering A, 2013, vol. 585, pp. 165-173.

8. Zhu S.M., Nie J.F. Serrated flow and tensile properties of a Mg-Y-Nd alloy. Scripta Materialia, 2004, vol. 50, no. 1, pp. 51-55.

9. Wang $\mathrm{C}$., $\mathrm{Xu}$ Y., Han E. Serrated flow and abnormal strain rate sensitivity of a magnesiumlithium alloy. Materials Letters, 2006, vol. 60, no. 24, P. 2941-2944.

10. Zhongjun W., Weiping J., Jianzhong C. Study on the Deformation Behavior of Mg-3.6\% Er Magnesium Alloy. Journal of Rare Earths, 2007, vol. 25, no. 6, pp. 744-748.

11. Denisov E.K., Mihlik D.V., Shibkov A.A., Zheltov M.A. Discontinuous deformation and structure of alloy Cu-Zn-Sn. Deformatsiya i razrushenie materialov, 2008, no. 9, pp. 6-11. (In Russian).

12. Shibkov A.A., Mazilkin A.A., Protasova S.G., Mihlik D.V., Zolotov A.E., Zheltov M.A., Shuklinov A.V. The influence of impurities on discontinuous deformation of the AMg6 alloy. Deformatsiya i razrushenie materialov, 2008, no. 5, pp. 24-32. (In Russian).

13. Krishtal M.M. Discontinuous fluidity in aluminium-magnesium alloys. Fizika metallov i metallovedenie, 1990, no. 12, pp. 140-143. (In Russian).

14. Mazen A.A. Effect of deformation temperature on the mechanical behavior and deformation mechanisms of $\mathrm{Al}_{-} \mathrm{Al}_{2} \mathrm{O}_{3}$ metal matrix composites. Journal of Materials Engineering and Performance, 1999, vol. 8, no. 4, pp. 487-495.

15. Puchi-Cabrera E.S. A constitutive description for aluminum-0.1 pet magnesium alloy under hot working conditions. Metallurgical and Materials Transactions A: Physical Metallurgy and Materials Science, 2003, vol. 34, no. 12, pp. 2837-2846.

16. Gouttebroze S., Mo A., Grong Ø., Pedersen K.O., Fjær H.G. A new constitutive model for the finite element simulation of local hot forming of aluminum 6xxx alloys. Metallurgical and Materials Transactions A: Physical Metallurgy and Materials Science, 2008, vol. 39 A, no. 3, pp. 522-534.

17. Zhang P., Li F., Wan Q. Constitutive equation and processing map for hot deformation of $\mathrm{SiC}$ particles reinforced metal matrix composites. Journal of Materials Engineering and Performance, 2010, vol. 19, no. 9, pp. 1290-1297.

18. Asgharzadeh H., Simchi A., Kim H.S. Hot deformation of ultrafine-grained $\mathrm{Al} 6063 / \mathrm{Al}_{2} \mathrm{O}_{3}$ nanocomposites. Journal of Materials Science, 2011, vol. 46, no. 14, pp. 4994-5001.

19. Rajamuthamilselvan M., Ramanathan S. Development of processing map for $7075 \mathrm{Al} / 20 \%$ SiCp composite. Journal of Materials Engineering and Performance, 2012, vol. 21, no. 2, pp. 191-196.

20. Mondal C., Singh A.K., Mukhopadhyay A.K., Chattopadhyay K. Effects of different modes of hot cross-rolling in 7010 aluminum alloy: Part II. Mechanical properties anisotropy. 
Metallurgical and Materials Transactions A: Physical Metallurgy and Materials Science, 2013, vol. 44, no. 6 , pp. 2764-2777.

21. Mondal C., Singh A.K., Mukhopadhyay A.K., Chattopadhyay K. Effects of different modes of hot cross-rolling in 7010 aluminum alloy: Part I. Evolution of microstructure and texture. Metallurgical and Materials Transactions A: Physical Metallurgy and Materials Science, 2013, vol. 44, no. 6, pp. 2746-2763.

22. Yang Y., Li F., Yuan Z., Qiao H. A modified constitutive equation for aluminum alloy reinforced by silicon carbide particles at elevated temperature. Journal of Materials Engineering and Performance, 2013, vol. 22, no. 9, pp. 2641-2655.

23. Gangolu S., Rao A.G., Prabhu N., Deshmukh V.P., Kashyap B.P. Hot Workability and Flow Characteristics of Aluminum-5 wV.\% B4C Composite. Journal of Materials Engineering and Performance, 2014, vol. 23, iss.4, pp.1366-1373.

24. Shuklinov A.V., Denisov E.K., Mihlik D.V., Zolotov A.E., Zheltov M.A., Shibkov A.A. The transition from a stable to an abrupt deformation caused by the change of composition and structure of Al-Mg alloy. Deformatsiya i razrushenie materialov, 2008, no. 3, pp. 30-35.(In Russian).

25. Mochalov N.A., Galkin A.M., Mochalov S.N., Parfenov D.Yu. Plastometricheskie issledovaniya metallov [Plastometer research of metals]. Moscow, Intermet Inzhiniring Publ., 2003, 318 p. (In Russian).

26. Meng L.J., Sun J., Xing H., Yu W.W., Xue F. Study of low-cycle fatigue of Al6XN austenitic stainless steel. Nuclear Engineering and Design, 2011, vol. 241, no. 8, pp. 2839-2842.

27. Novikov I.I. Teoriya termicheskoi obrabotki metallov [Theory of heat treatment of metals]. Moscow, Metallurgiya Publ., 1978, 391 p. (In Russian).

28. Belyaev A.I., Bochvar O.S., Buynov N.N. Metallovedenie alyuminiya i ego splavov [Physical metallurgy of aluminium and its alloys]. Moscow, Metallurgiya Publ., 1983, 280 p. (In Russian).

29. Kugler G., Turk R. Modelling the dynamic recrystallization under multi-stage hot deformation. Acta Materialia, 2004, vol. 52, no. 15, pp. 4659-4668.

30. Serajzadeh S. Modelling dynamic softening processes during hot working. Materials Science and Engineering A, 2005, vol. 404, no. 1-2, pp. 130-137.

31. Lin Y.C., Chen X.-M. A critical review of experimental results and constitutive descriptions for metals and alloys in hot working. Materials \& Design, 2011, vol. 32, no. 4, pp. 1733-1759.

32. Kodzhaspirov G.E., Terentyev M. Modeling the dynamically recrystallized grain size evolution of a superalloy. Materials Physics and Mechanics, 2012, vol. 13, no. 1, pp. 70-76.

33. Rudskoy A.I., Kodzhaspirov G.E., Erentev M.I. Evolution of the structure and properties of $\mathrm{Ni}-29 \mathrm{Cr}-9 \mathrm{Fe}$ at high-temperature plastic deformation: Experiment and modeling. Deformatsiya $\mathrm{i}$ razrushenie materialov, 2013, no. 5, pp. 43-48. (In Russian).

34. Momeni A., Ebrahimi G.R., Jahazi M., Bocher P. Microstructure evolution at the onset of discontinuous dynamic recrystallization: A physics-based model of subgrain critical size. Journal of Alloys and Compounds, 2014, vol. 587, pp. 199-210.

35. Guiqing Ch., Gaosheng F., Wenduan Ja., Chaozeng Ch., Zechang Z. Mathematical model of dynamic recrystallization of aluminum alloy 3003. Metallovedenie i termicheskaja obrabotka metallov, 2013, no. 4, pp. 51-56. (In Russian).

36. Wenduan Ya., Gaosheng F., Guiqing Ch. Kinetic model of dynamic recrystallization of aluminum alloy 1235. Metallovedenie i termicheskaja obrabotka metallov, 2012, no. 4, pp. 23-26. (In Russian).

37. Haimovich A.I., Surkov O.S. Fenomenological model of dynamic recrystallization of aircraft alloys. Vestnik Samarskogo gosudarstvennogo aerokosmicheskogo universiteta, 2009, no. 3-3(27), pp. 150-153. (In Russian).

38. Gourdet S., Montheillet F. A model of continuous dynamic recrystallization. Acta Materialia, 2003, vol. 51, no. 9, pp. 2685-2699.

39. McQueen H.J., Kassner M.E. Comments on a model of continuous dynamic recrystallization proposed for aluminum. Scripta Materialia, 2004, vol. 51, no. 5, pp. 461-465. 
40. Hallberg H., Wallin M., Ristinmaa M. Modeling of continuous dynamic recrystallization in commercial-purity aluminum. Materials Science and Engineering: A, 2010, vol. 527, no. 4-5, pp. $1126-1134$.

41. Eivani A.R., Zhou J., Duszczyk J. Numerical modeling of subgrain growth of hot extruded $\mathrm{Al}-4.5 \mathrm{Zn}-1 \mathrm{Mg}$ alloy in the presence of nanosized dispersoids. Computational Materials Science, 2014, vol. 86(15 April) pp. 9-16.

42. Konovalov A.V. Viscoplastic model for the resistance of metals to high-temperature deformation. Metally, 2008, vol. 2008, no. 5, pp. 456-459.

43. Konovalov A.V., Smirnov A.S. Viscoplastic model for the strain resistance of 08Kh18N10T steel at a hot-deformation temperature. Metally, 2008, vol. 2008, no. 2, pp. 138-141.

44. Konovalov A.V., Smirnov A.S., Mazunin V.P., Kokovikhin E.A., Muizemnek O.Yu. Modeling of strain resistance of $08 \mathrm{Kh} 18 \mathrm{~N} 10 \mathrm{~T}$ steel and AMg6 alloy at high rates and temperatures of strains. Deformatsiya i razrushenie materialov, 2012, no. 7, pp. 7-12. (In Russian).

45. Smirnov A.S., Konovalov A.V., Muizemnek O.Yu. Identification of model of strain resistance subject to volume fraction of dynamic recrystallization. Deformatsiya i razrushenie materialov, 2013, no. 9, pp. 7-13. (In Russian).

46. Speedy C.B., Brown R.F., Goodwin G.C. Teoriya ypravleniya. Identifikatsiya i optimalnoe upravlenie [Control theory. Identification and optimal control]. Moscow, Mir Publ., 1973, 248 p. (In Russian).

47. Dziaszyk S., Payton E.J., Friedel F., Marx V., Eggeler G. On the characterization of recrystallized fraction using electron backscatter diffraction: A direct comparison to local hardness in an IF steel using nanoindentation. Materials Science and Engineering: A, 2010, vol. 527, no. 29-30, pp. 7854-7864.

48. Kolychev B.A., Livanov V.A., Elagin V.I. Metallovedenie i termicheskaya obrabotka tsvetnykh metallov i splavov [The metallography and heat treatment of nonferrous metals and alloys]. Moscow, MISSIS Publ., 1999, 416 p. (In Russian).

49. Konovalov A.V., Smirnov A.S. Simulation of strain resistance of AMg6 alloy under hot temperature deformation. Deformatsiya i razrushenie materialov, 2008, no. 5, pp. 33-36. (In Russian). 